\title{
A Brief Critique of Speculative Materialism: The Rise of A Science Fundamentalism
}

\author{
Thamalu Maliththa Piyadigama
}

\begin{abstract}
A new current of philosophy emerged with Quentin Meillassoux's book After Finitude. Meillassoux's philosophy which is identified as Speculative Materialism promises to establish discourses about objective reality. His tool, the principle of unreason, is analysed in this paper to see whether he succeeded. We can identify this philosophical project as a fundamentalism of science. The limitations of Speculative Materialism are discussed, and it is compared to another philosophy, Constructive Relativism.
\end{abstract}

\section{Introduction}

When the French philosopher Quentin Meillassoux published his "After Finitude", ${ }^{1}$ a new term "correlationism" came to the philosophical discourse. This "correlationism" indicates a hidden feature in Western philosophy after Kant. This magnificent identification tells us that postKantian philosophers have totally neglected any trial to understand the nature of the external (in the sense mind independent) world. On the contrary they emphasize the relation between subject and object or thought and being. External world or objective reality has been taken as either impossible or meaningless by some while other correlationists avoid any effort to observe the nature of objective reality though they just accept its existence without any justification. According to the classification of Meillassoux latter are the weak correlationists including Kant himself. Meillassoux sees that correlationism as the enemy and Kant who called himself a revolutionist as a counter-revolutionist.

Anyone who has studied history of philosophy knows why Kant is considered to be the person who did Copernican revolution in philosophy. He ended up the age old struggle between empiricism and rationalism to be the genuine source of knowledge by synthesizing both into his transcendental idealism. This effort to answer how sciences (mathematical and empirical) are possible has humorously put science into a pathetic situation. As elementary education convinces us the church and religion in the medieval period was the Pandora's box of all oppression and backwardness and it was science the emancipator and courageous rebellion that struggled against the overwhelmed darkness of Feudal Age to push the western society (and

\footnotetext{
${ }^{1}$ After finitude: An essay on the necessity of contingency Meillassoux, Quentin 2010, Bloomsbury Publishing
} 
then the world) to the light of forwardness and freedom. Though careful historians and anthropologists have written in their books that this is not the complete picture and a large part of this is factually incorrect, this is the mythology that modernity wants us to believe at least in our childhood when we build up our foundations of worldview. ${ }^{2}$ We can find traces of the impact of this myth in Meillassoux's writings also. When he identifies religion as a problem and the source of harmful extremisms he has neglected how science also has become a source of harmful extremisms (as in the case of racism of Shockley) and how the science has become rigid and oppressive being a barrier to its own development as Feyerabend described in his texts. ${ }^{33}$

When science came into the scene and took the centre stage ancient religious texts had to be re-interpreted and the 'literal' meanings of those texts were discouraged. (This was apparently after some resistance as in the Galileo's case.) The connection of philosophy and religion or the theology was the only survival mode of religious texts. After Kant

The history repeated itself. Science discourses about an external world (objective reality).

To say that external world is unknowable even if it exists is to say that statements of science should not be understood literally. Once what science did to religion is done to science itself by the philosophy. This rejection of 'literal meaning' of scientific discourse has finally imprisoned the classical enemy of religion making space for not only theologians but also for religious fetishists and so-called fundamentalists (who call us to go to 'fundamentals' or literal reading again). Therefore, after Kant philosophers' task was not to strengthen the philosophical foundation of science but to re-interpret literal texts of scientists. Meillassoux who sees Messiah in science considers this as a counter-revolution.

Meillassoux's project is to overturn this so-called counter-revolution. He calls us to go back to the literal reading of science. Therefore, we can call him a fundamentalist of science. Since post-Kantians did to science what science had done to religion, the literal meaning of one discourse cannot reject literal meaning of the other. (We should keep in mind that even in the time literal meaning of religious texts was in the dominance it could not reject 'non-literal' meanings of science. For example, Cardinal Bellarmine was well prepared to accept heliocentrism as a useful mathematical tool though he was doubtful to take it as reality. ${ }^{45}$ ) Therefore, correlationists have put science and religion to the equal ground and the real battle is now should be among theologians and (science) philosophers. How ever there is no clear distinction or struggle between them to be seen. They go hand in hand. (For example we can consider Meillassoux's failed hero DesCartes.) Meillassoux wants to empower literal meanings of science over religion since he believes that the philosophers' contribution to science has become unimportant and secondary to the scientists after Kant. This can be compared with the attitude of a religious fetishist about theologians. We can identify Meillassoux as a science fetishist. However, he is not the type of 'ignoring fetishist' who goes on believing texts ignoring or naively avoiding the whole world of criticism. He identifies the problem and understands that the problem should be overcome within. Zizek is correct when he says After Finitude is (Lenin's) Empirio Criticism re-written for $21^{\text {st }}$ century. ${ }^{6}$ Meillassoux identifies the key to open the door to external world as to reject the principle of sufficient reason and to absolutize

\footnotetext{
${ }^{2}$ Copernicus' secret: How the scientific revolution began, Repcheck, Jack 2007, Simon and Schuster

${ }^{3}$ Against method, Feyerabend, Paul 1993, Verso

${ }^{4}$ How to defend society against science, Feyerabend, Paul, "Introductory readings in the philosophy of science", 1998, pp 54-65, 1975, Prometheus Amherst, New York

${ }^{5}$ To save the phenomena: An essay on the idea of physical theory from Plato to Galileo, Duhem, Pierre

, University of Chicago Press

${ }^{6}$ Less than nothing: Hegel and the shadow of dialectical materialism, Žižek, Slavoj 2012 Verso Books
} 
unreason. In other words, capacity to be other without any reason is the way to break through the finitude of knowledge (correlation). However, this forces us again to avoid literal meanings of science because scientists do say they explain or discover reasons behind the world rather than just describing it. Then scientists are no more than astrologers who say they are describing human life in terms of planetary motion without any reason while there is capacity to be other. Then will it be the astrology the ultimate genuine form of knowledge? Clearly no scientist (as the way literally scientists are) will like this. Meillassoux is as counter-revolutionist as Kant if Kant is so. Science discourses with the language of reason. Meillassoux calls us to re-interpret the texts with another language. Correlationists say us that there is no point of debating over the literal meanings of statements of science and religion because they are about an (at least) unknowable objective reality. In contrast Meillassoux (if he succeeded) provides space for literal meanings again but he also avoids the fight because both discourses are 'unreason' so it is impossible to establish the necessity of either. Both are capable to be other without reason. (Meillassoux so often conflates the contingency with temporal change that careless one might find the previous sentence awkward. This is elaborated in later parts of this paper.) Correlationists throw literal texts out of the game and remain the battle to theologians and (science) philosophers who like to maintain ceasefire and Meillassoux if he succeeded on the other hand pulls literal texts back into the game but is unable to avert the ceasefire. This is the paradox of Meillassoux's scientific fetishist fundamentalist project. The next problem is now whether he found the key to open the

Door to great outdoors (objective reality) or even showed that there is such outdoor.

In this process Meillassoux's greatest enemy is not Kant who said that there is objective reality though its unknowable but the post-Kantian who said it is unthinkable and impossible or meaningless to talk about an objective reality. His first step was to justify the existence and noncontradictory nature of objective reality (thing in itself) which Kant just stated without any justification. Next step was to reveal its mathematical nature.

\section{Strong Correlationist and Absolute Idealist}

Weak correlationists like Kant say that thing in itself is thinkable but unknowable. Strong correlationists say thing in itself is unthinkable also but they did not say it is impossible. Absolute Idealists (as Graham Harman categorizes) absolutize correlation. ${ }^{7}$ They made a razor out of correlation and use it to cut down everything uncorrelated. Any term which denotes the uncorrelated or unthinkable is just a mere word and the idea of that term contains is impossible, inexistent and excluded. Objective reality (thing in itself) is unthinkable so it is impossible and there is no objective reality. Death or my not-being is unthinkable to me since I am the one who thinking that -so I am- (content of thought contradicts the act of thinking.) so there is no death. This is a full-blown idealism of ever existing mind.

The problem is how the strong correlationists can rejects absolute idealist position. This is the second principle of strong correlation. A correlated absolute has no reason to be as it is now. I cannot say unthinkable is impossible because I cannot give reason why thinkable must be as it is. I cannot refuse my not being (death) due to lack of reason of my being. Correlated existence is a fact and there is no way to establish its necessity. As Meillassoux says every thought of something being a fact (not a necessity) is the way to raise the unthinkable to a possibility from impossibility. Meillassoux's effort is to absolutize this facticity (capacity to be other without reason) to raise unthinkable from possibility to actuality.

\footnotetext{
${ }^{7}$ Quentin Meillassoux: Philosophy in the Making: Philosophy in the Making, Harman, Graham 2011 Edinburgh University Press
} 


\section{Meillassoux's Method to Justify Kantian Thing-in-Itself.}

There are two propositions on thing-in-itself by Kant.

a) Thing in itself is non-contradictory.

b) Thing in itself exists.

Meillassoux establishes this from the principle of unreason. It is a fact that something is like this rather than something else. There is no reason for that. Something is contingent (could be something else). It is a fact. This is facticity of the thing. All 'entities' are contingent. Facticity is in every entity. Therefore, no entity is necessary.

1) There is no necessary entity. (This is not limited to the realm of thought)

Then he says facticity of entities is a necessity. Otherwise facticity is a fact by absolutizing second order facticity which contradicts content of the deed. He calls this factuality (that facticity is not a fact.)

2) Facticity of entity is necessary.

Contradictory entity should be necessary since this entity be and not be simultaneously resulting that it is being even it is not be. Hence by 1 it is impossible. Then contradictory entities are impossible. Then if thing in itself exists it has to be noncontradictory.

a) Thing in itself is noncontradictory.

Since facticity is a necessity there should be factical things since otherwise there is no facticity. Therefore, since facticity is necessity annihilation of humans should not fall into nothing since the necessity of facticity necessitates existence of factical things. Therefore something is rather than nothing.

b) Thing in itself exists.

\section{Problem and The Limitation of the Argument}

Meillassoux's fundamental step is to presume strong correlationist's victory over absolute idealist. We cannot say unthinkable is impossible since we cannot say (with reasons) something is rather than something else. In another way I cannot reject my not-being since I cannot necessitate my being with reasons.

Absolute idealist will refute this position simply saying she can necessitate her being rather than not being. Since unthinkable is impossible my not-being is impossible making the only possibility of me is to be. In other words, reason why I am is that the impossibility of I am not. (My being is. My not being is not. Therefore, there is no alterity or difference of my being.)

Another absolute idealist will refute that claim in the following way. My being is capable of being other but this other is not the unthinkable not-being of me but different thinkable alternatives of my being. I can be a human and out of reason there was capability to be a bird and I can imagine how my being is as a bird. In Buddhist discourse (though it is not an absolute idealist doctrine) reincarnation is stated as to be neither me nor another. Strong correlationist can then reply that it is just my mode of being contingent but not my being 
itself. To this absolute idealist may challenge strong correlationist to define my being and argue that there is no my-being beyond my way of being. Therefore capacity

to be other without reason necessary means capacity to be other which is also thinkable.

Meillassoux's proposition that there is no necessary entity is endangered by absolute idealism as we saw above. However, there is another way that the absolutizing of facticity can be challenged. This time is by correlationism. Meillassoux missed the point that there are no order for two principles. It is just a historical matter what comes first. As Meillassoux clearly understands Hume's project has the capability of concluding as principle of unreason even before Kant. (This is the way a considerable number of amateurs understand Hume

actually.) We can see that facticity can be challenged by correlation itself. The first way is that if something is unreason it is unreason to us. We cannot deny the possibility of a superiority mind or being that can grab the reason behind the thing. Unthinkability of such a being does not indicates its impossibility. On the other hand, the different reasons can be for different minds, so unreason is not the only option. (This means we should except relative existence of reasons rather than absolute existence/inexistence of reason.) This impossibility of absolutizing facticity is in defence of correlationism against Speculative Materialist. Hence, correlationist circle provides space to the contingency of reason also making unreason is non-necessary.

The weakest point of Meillassoux's argument is when he says contradictory entity is necessary. In the end of third chapter he accepts that he conflates contradiction with inconsistence (where everything is contradicted). He well aware that there are para consistent logic systems, but he does not care them just thinking these systems are not developed as natural logic (so just only an artificial game of symbols). He is not aware of the Catuskoti logic in Buddhist discourse. Nalin de Silva, Sri Lankan philosopher who proposed a philosophy named Constructive Relativism has developed a systematic interpretation of fourfold (Catuskoti) logic. This is a para consistent logic system. In his critique of Hegelian logic Silva explains Hegelian notion of infinite contradiction is incomplete. ${ }^{8}$ True, False, True and False, Neither True or False are four folds of Catuskoti logic. Meillassoux misses such alternatives when he says contradictory entity cannot change. Contradictory entity can change its fold to a noncontradictory fold or the other contradictory fold. Therefore, contradictory entity is not necessary because it can change its state to at least uncontradictory pure existence or pure inexistence. Meillassoux's unawareness cannot be neglected since he started presuming unthinkable is not impossible. Then absence of knowledge about para consistent logic systems is not anyway justifies ignoring them. On the other hand, one contradiction does not make incapable of change since there are other features to change. As we saw above even contradictory feature can change.

His next argument is that it is necessary factical things to exist for facticity to be. Otherwise facticity is a fact. But facticity is not a fact. As he claimed earlier This is a vulnerable part of Meillassoux's argument. Nalin de Silva shows that there is a circle in deduction. When we construct general statements, we have presumed whole set represented by the statement always behaves like that. It is an assumption. Then we use that statements to deduct specific incidents, but what we obtain is just what we unintentionally presumed beforehand for that specific incident also. ${ }^{9}$

Core of Meillassoux's arguments is that facticity is not a fact. He got this general statement by generalization. The special incident which he used deduction for is that there is nothing. Then we can see three cases: There is nothing. There are necessary things. There are nonnecessary things only.

\footnotetext{
${ }^{8}$ Formalism in Dialectic - Apohakaye Rupikaya, de Silva, Nalin, Chinthana Parshadaya, 1994 Sri Lanka

${ }^{9}$ Ape pravada, de Silva, Nalin 2010 Visidunu Publications, volume 3
} 
Meillassoux showed that there are no necessary things since 'there is no reason'. Then according to first alternative if there is nothing, 'there is no reason' is satisfied because there is nothing to be a reason nor nothing to request reasons. Clearly 'there is no reason' is not a quality of 'something'. Only if are there non-necessary things no reason can become a feature of them as facticity. (There are things without reasons making reasonless -or facticity- a quality of them.) Then we can clearly see facticity is not necessary. Then the problem to inspect is that if this implies facticity of facticity. However, we should aware that Meillassoux analysed facticity of entities but not of features. Facticity is not a necessary entity and it is even not an entity at all. It is a feature of entities. Then we can ask him whether facticity feature exists is a fact. This difference cannot resolve the problem. If there is nothing, facticity feature is not there and if there is something, facticity must be a feature. Is this an infinite regression? We see that it is not since the domain (entities, features etc.) of facticity will change in each step. Meillassoux simply says that this is an infinite regression, and this cannot go further by absolutizing facticity (in any order) while rejecting its content at the same time. (We can see that it is not the same we accept and change since the domain is different.) If he was careful enough to test his claim at least for so-called second order facticity he might understand the problem of his argument. Let us take facticity of facticity as an absolute. Therefore, any feature which is necessary is impossible. (Here we can see a little problem. Absolutizing facticity or correlation is meaningful because those are defined to a (or the) set of entities. Facticity of just facticity is a specific situation so to absolutize it we may have to call upon facticity of features. We can wide or narrow this scope than the set features. It does not affect to our argument until the domain contains facticity.) Now facticity is a feature. Then to be a possible feature facticity must be non-necessary. There are only two ways this can be. There should be nothing (to be factical) or there should be a necessary entity. Since we readily understood there is no necessary entity the valid alternative is that there should be nothing. Therefore, absolutizing of second order facticity concludes establishing the necessity of the annihilation of every factical being. Then we have justified the opposite of what Meillassoux did. As a summary if we say facticity is not only for entities but also for features annihilation of all factical beings is an absolute necessity.

If we carefully inspect further, we can understand the mistake of Meillassoux's word game. What Meillassoux shows us is that there is no reason behind anything. However when he converts 'no reason' to 'facticity' it is not just giving a new name. Facticity is a feature of entities while 'no reason' is not a feature but rather it is the absence of a feature. When we say 'facticity is' we have assumed both that there is no reason and there is some entity. 'There is no reason.' is not simply 'There is facticity.' Therefore when he constructs the universal statement that facticity is necessary (rather than reason is impossible) he has already 'assumed' that there is 'something' always. If we go on with'no reason'we can see that for the necessity of'no reason' there is no need of things that are 'no reason'. If it is nothing, then clearly there is no reason at all. Therefore, it is erroneous to prove existence of in-itself with the necessity of facticity because it is necessary that there is no reason but not the facticity.

If we neglect these weaknesses at the heart of Meillassoux's argument and consider factical things should be then we can see that it still does not imply that annihilation of all living beings will not collapse into nothing. If that annihilation happens there is the possibility of regeneration of living beings so there is facticity although it collapsed into nothing. Therefore, facticity of something can be obtained through facticity of 'given' only. (Facticity is a feature we give and not a feature there in itself. If we are not there is nothing but the possibility of us to become which is correlated.)

\section{Meillassoux's conflation of contingency with the change}


Meillassoux often speaks about perishing and changing in his descriptions of contingency. However, we must emphasize here that contingency is not only a temporal behaviour. We observe and Aristotle explained matter as continuous but modern science convinces us that it is discreet. Classical theory of metals says us metals are cations in a sea of electrons while quantum physics suggests otherwise. Philosophically there is no ultimate reason to establish any of those explanations, so these states of beings are just facts and therefore contingent. Even bare eye observations are relative to the knowledge and organs. Therefore, facticity and contingency are always there and not an event to happen. Facticity of my being does not just establish "a death". We cannot establish our being in the very moment we think. "I think therefore I am." cannot go through messes of facticity. Therefore, absolutizing of correlation to say that 'my not-being is not' cannot be challenged by facticity since both my-being and notbeing can be rejected claiming both are illusionary. Facticity does not open the door to accept the possibility of my not-being but opens door to question my being as well.

\section{Mathematical Nature of Thing-in-Itself}

In this paper we do not go to discuss the Meillassoux's trial to show the ability of mathematics to describe the nature of thing-in-itself. Meillassoux also accepts that here he is only partially succeeded. DesCartes provided mathematicians the full access to objective reality since God who is perfect does not deceive mathematicians who use reasoning perfectly. Meillassoux's way of addressing Hume's problem by mathematics even if he succeeded will only show mathematics would be required in basic philosophical foundation but it is not sufficient to provide it full access to the great outdoors. In my point of view Meillassoux's mathematical knowledge is limited. Though he knows ZFC set theory the probability theory he is analysing with it is a naive one. He did not pay attention to the modern formulations of probability and did not discuss anything regarding the relation of probability and ergodicity. If he carefully studies mathematics, there is hope that he may be able to build a stronger argument to solve Hume's problem with the use of ergodicity. (There is whole set of possible states for a specific event so there is no reason for a one state to be. However, if we tried the same event for large number of times the totality of results will visualize probabilities by proportion if the event is ergodic while there is no reason for an event to be ergodic at all.) It is highly questionable that whether probability becomes undefined just because of the untotalizability of event space. (Meillassoux does not discuss axiomatic probability theory.) The tendency of a uniformly distributed continuous variable to change frequently cannot be rejected by saying that the infinite elements of the event space makes the probability of an individual value undefined or zero (at the limit). Even if the cardinality of event set is alpha nought or even higher there are ways to define probability and there will be frequent changes accordingly if the variable is ergodic. Meillassoux cannot simply state untotalizability of the event space to reject frequent random change.

However, the capability of mathematics to grab the objective reality has a serious problem that was unknown at DesCartes time. In his time, it was only one geometry and one mathematical discourse. There was the hope of completion of that discourse. Objective truth is considered to be consistent while false was hoped to rise contradictions in the future helping mathematicians to eliminate those false. However, after the construction of non-Euclidian geometries we know that mathematics is not a unique discourse. Physics in this century is debating about what is the 'correct' geometry which is a very different situation to DesCartes' era. After the Hilbert project failed and its death was announced by Godel's theorem the problem has become complicated. 
The limitations of mathematics have been showed off themselves in the discourse of mathematics itself. Therefore, a philosopher can do very little to empower mathematics again now as the key to truth. If any philosopher succeeds to provide mathematics the key to great outdoors, mathematics itself will raise the question that which mathematics is the key. Even if any mathematics may be the key then the distance it can go will be limited by Godel's theorem. We have to let contradictions or to add unprovable statements again and again without an end into our axiom set. ${ }^{10}$ According to Meillassoux thing-in-itself is non-contradictory so only option is to go on adding axioms without an end. When we need to add an axiom there it occurs the problem which mathematics is accessing the thing-in-itself. Even Meillassoux's principle of unreason does not go well with the style of mathematics. Therefore, Meillassoux can do little with mathematics if he is not going to create a new discourse of mathematics. However, that is task of a mathematician and it is not the mathematics we means by its name now.

\section{Constructive Relativist Response to Meillassoux}

Constructive Relativism, the philosophical project started by Nalin de Silva's 'Mage Lokaya' ('My World'), explains that my knowledge about the world is completely what the knowledge I gave to the world. ${ }^{11}$ Therefore, the knowledge is constructed and the construction is the source of minds (subjects) and objects an our knowledge of the world is given as 'objects are constructed by subjects'. Since it has been given such we can say world is a construction of mind and mind is also a construction of itself. This knowledge is also given. All knowledge we construct is lies (Boru) as they inherit the tension that the notion of a sort of existence is needed to use that knowledge while there is no ground for objective existence. All existence, being and reason are constructed and the fact that mind (subject) is the constructor is also no more than givenness.

Constructive Relativists accept that there is no necessary entity or ultimate reason because all entities and reasons are constructed lies. However, they are possible as constructed lies. ${ }^{12}$ Thing-in-itself is impossible because all ideas about thing-in-itself are constructed. There is no discovery but the construction. Ancestrality is a problem of conflating observer with the constructor. Observation or the observer-observed relation is only a mode of givenness for some constructions. Constructed concepts (lies - Boru) are given with a history. Numbers and other mathematical entities are not a priory knowledge. They are constructed by induction and abstraction. The source of misrecognition of a priory knowledge and the question of ancestrality occurs in the mistaken conflation of observer with the constructor.

In contrast to Meillassoux constructive relativists hold that reasons are lies and there is no necessary entity or feature because they are lies. However, this does not follow there is thing in itself as in speculative materialism. Thing in itself is a lie so it goes against with its meaning and so there is no thing in itself. Rather than possibility to of grasping my not being constructive relativism questions my being and say I am as a lie. Our own existence is a lie which is given.

\footnotetext{
${ }^{10}$ On formally undecidable propositions of Principia Mathematica and related systems, Gödel, Kurt,1992, Courier Corporation

${ }^{11}$ Mage lokaya, de Silva, Nalin, Chinthana Parshadaya,1992 Sri Lanka

${ }^{12}$ Ape pravada,de Silva, Nalin 2010 Visidunu Prakāśakayō, volume 3, Sri Lanka
} 
